\title{
Age and sex differences in prevalence and clinical correlates of depression: first results from the Irish Longitudinal Study on Ageing
}

\author{
Claire O. Regan ${ }^{1}$, Patricia M. Kearney ${ }^{2}$, George M. Savva ${ }^{1}$, Hilary Cronin ${ }^{1}$ and Rose Anne Kenny ${ }^{1}$ \\ 'The Irish Longitudinal Study on Ageing (TILDA), Trinity College Dublin, Dublin, Ireland \\ ${ }^{2}$ University College Cork, Cork, Ireland \\ Correspondence to: C. O. Regan, MSc, E-mail: oreganc1@tcd.ie
}

\begin{abstract}
OBJECTIVE:

The risk of depression is increased by physical illness; however, the nature of this relationship is complex and unclear. Here, we explore the prevalence and clinical correlates of depression, with particular emphasis on factors representing consequences or physical manifestations of disease and identify age and gender differences in their effects.
\end{abstract}

\section{METHODS:}

A population-representative sample of 8175 community-dwelling adults aged 50 years and over participated in the first wave of The Irish Longitudinal Study on Ageing. The primary outcome measure was clinically significant depressive symptoms defined by a score of 16 or greater on the 20-item Centre for Epidemiologic Studies Depression scale.

\section{RESULTS:}

Overall, $10 \%$ (95\% Cl: 9-11\%) of adults reported clinically significant depressive symptoms. Physical illness is associated with depressive symptoms only in adults 65 years and older; in adults aged 50-64 years, the association is mediated by medication use, and this age difference is statistically significant $(p<0.00)$. Irrespective of age, chronic pain and incontinence were stronger predictors of depression in men (interaction effects $p<0.00$ ) CONCLUSIONS: Our findings identify age-specific and gender-specific clinical markers for depression risk among the older population, which may identify those more likely to present with depression in community settings.

\section{Introduction}

Depression is the leading cause of morbidity and mortality worldwide (Murray and Lopez, 1997), but knowledge about prevention is lacking, especially among older people for whom underdiagnosis and undertreatment is a significant issue (Licht-Strunk et al., 2005). In older adults, physical illness has been well established as one of the most important risk factors for depression, and its dominant role may be one of the most significant differences between latelife depression and depression in younger adults (Beekman et al., 1995c, Beekman et al., 1995a). A number of diseases have been shown to have direct aetiological links with depression, for example, vascular disease (Alexopoulos et al., 1997) and Parkinson's disease (Cummings, 1992); however, findings from community-based studies suggest that general aspects of physical health, such as the level of functional impairment and perceived health, are more important correlates of depression than specific diagnoses (Kennedy et al., 1989, Prince et al., 1997).

The prevalence of major depressive disorder ranges from $1 \%$ to $5 \%$ among community-dwelling older adults (Hasin et al., 2005), and approximately 15\% experience clinically significant depressive symptoms (Blazer, 2003). The prevalence of major depressive illness appears to diminish as people become older; 
however, the incidence of clinically significant nonmajor forms of depression increases with advancing age (Park and Unützer, 2011). At least half of all older adults with major depression are experiencing a new condition arising for the first time in old age (Brodaty et al., 2001, Bruce et al., 2002). It is therefore important to identify factors that lead to depression in older adults so that prevention can be targeted at high risk groups. Previous studies have focused on risk factors for depression in all adults 55 years and older or 65 years and older (Beekman et al., 1995b, Schoevers et al., 2000 ) or explored risk factors in the 'oldest old', that is, adults who are 75 or 80 years and older (van't VeerTazelaar et al., 2008). Although not directly comparing young-old and old-old cohorts, these studies suggest that long-standing vulnerability factors, such as family and personal histories of depression, are less important in older adults, whereas risk factors such as physical illness, cognitive decline and a diminishing social network become more significant with increasing age (Fiske et al., 2009).

Although it is well recognised that women are more likely to suffer from depression than men (Djernes, 2006), gender differences in risk factors for depression are not well studied in older people. Rates of depression appear to be higher in older women than older men but with a smaller gender gap than among younger people (Djernes, 2006). Many social and health-related aspects of ageing differ between men and women; therefore, identifying variables that indicate greater risk of depression in different genders and investigating whether risk factors associated with depression differ by gender are important tasks.

The present study sought to determine the prevalence of depressive symptoms in a large populationrepresentative sample of community-dwelling older adults. We explore clinical correlates of depression with particular emphasis on factors representing consequences or physical manifestations of disease. Older adults are not a homogenous group; therefore, we hypothesised that clinical correlates of depression would show age-specific and gender-specific patterns of distribution.

\section{Methods}

\section{Study design}

We analysed data from the first wave of The Irish Longitudinal Study on Ageing (TILDA) collected between October 2009 and February 2011. Full details of the sampling procedure and response have been described elsewhere (Kearney et al., 2011). In short, TILDA is a study of people who are 50 years and older (and their spouses or partners of any age) and resident in Ireland. A nationally representative sample was drawn from the Irish Geodirectory. Participants completed a computer-assisted personal interview in their own homes, which included detailed questions on their social, economic and health situations. At baseline, 8504 participants were recruited to the study including 8175 respondents aged $\geq 50$ years and 329 younger partners of eligible individuals. The response rate to the study was $62 \%$. The study was approved by the Faculty of Health Sciences Research Ethics Committee, and subjects were required to provide written informed consent prior to participation in the study.

\section{Measurements}

The primary outcome measure for this analysis was case-level depressive symptoms defined by a score of 16 or greater on the 20 -item Centre for Epidemiologic Studies Depression scale (CES-D). The CES-D generates a total score with a range between 0 and 60 with higher scores indicating greater depressive symptoms. A cut-off score of 16 has been shown to have a sensitivity of $100 \%$ and specificity of $88 \%$ for major depressive disorder in an older population (Beekman et al., 1997)

In the present study, we considered sociodemographic and clinical correlates depression. Sociodemographic factors included age, gender, education and marital status. Clinical factors included chronic diseases, cognitive impairment, functional limitations, pain, sensory impairment, medication use and lifestyle characteristics (alcohol and substance abuse, smoking). Participants were asked whether a doctor ever told them they had any of the following diseases: heart attack, heart failure, angina, cataracts, hypertension, high cholesterol stroke, diabetes, lung disease, asthma, arthritis, osteoporosis, cancer, Parkinson's disease, peptic ulcer or hip fracture. The number of chronic diseases was calculated by summing up all specific diseases reported to be presented by a participant. Participants also reported whether a doctor had ever told them they suffered from alcohol or substance abuse or whether they had suffered from urinary incontinence in the previous year.

Measures of cognitive function included immediate and delayed recall of 10 words to assess memory and semantic verbal fluency (number of animal names generated in $1 \mathrm{~min}$ ), which is both a measure of executive function and language. These measures of 
cognitive function have been utilised in other large ageing studies, for example, the English Longitudinal Study on Ageing (Steptoe et al., 2012) and the Health and Retirement study in America (Ofstedal et al., $2005)$. Low verbal fluency was defined as $1.5 \mathrm{SD}$ below the weighted mean. This equated to $\leq 10$ words in adults aged 50-64 years (mean $21, \mathrm{SD}=7$ ) and $\leq 9$ words in adults 65 years and older (mean $18, \mathrm{SD}=6$ ). Disability was examined by asking participants whether they had any long-standing illness, disability or infirmity that had troubled them or was likely to affect them over a period. If the answer was yes, they were then asked whether the illness limited their activities in any way. From the answers to these questions, a variable was derived to indicate the presence of a limiting long-standing illness (LLI). Participants were asked to list all medications (prescription and nonprescription) that they took on a regular basis, and the total number of medications was summed (excluding antidepressants). Chronic pain was assessed by asking participant if they often suffered from pain. If the answer was yes, they were asked whether most of the time the pain was mild, moderate or severe. Participants who reported moderate or severe pain were classified as suffering from chronic pain. Sensory impairment was examined by asking participants to rate their vision and hearing using a 5-point Likert scale ranging from excellent to poor. Adults who rated their vision/hearing as fair or poor were classified as having visual impairment.

\section{Statistical analysis}

Univariate logistic regression was used to identify correlates of depressive symptoms. These factors were then added into a multivariate model in three blocks to assess possible mediating relationships between factors. The first block included sociodemographic factors. The second included chronic disease, cognitive impairment and lifestyle factors, and the third block included factors representing consequences or physical manifestations of disease.

To examine how correlates of depressive symptoms varied by age and sex, multivariate models were estimated separately in four groups defined by gender and age (50-64 vs. $65+$ ). To test whether factors were significantly different between age and gender groups, a final model was then estimated on the basis of all participants including the interaction terms.

Sample weights were applied and calculated by comparing the TILDA sample with the Irish population with respect to age, sex and educational attainment (Kearney et al., 2011). All analyses include an adjustment for clustering of responses at the household and geographical primary cluster levels.

\section{Results}

\section{Sample characteristics}

The sample consisted of 8175 older adults (mean age 64 years, SD 9.7 years, range $50-99$ years, $52 \%$ women). A total of 8032 participants successfully completed the CES-D ( $98 \%$ of sample). People with known or suspected dementias were specifically not recruited by interviewers to the TILDA study at baseline, so few people are classified as having moderate or severe cognitive impairment in our study. Over a third (38\%) of participants had only primary education (8 years or less of formal schooling), and over two thirds $(68 \%)$ of the sample were currently married (Table 1$)$.

\section{Prevalence of depressive symptoms by age and sex}

The overall prevalence of clinically significant depressive symptoms in our sample was $10 \%$. The highest prevalence $10.7 \% \quad(95 \%$ CI: $10-12 \%)$ was found among adults aged 50-64 years, declining to $9.1 \%$ (95\% CI: $8-11 \%)$ for adults aged $65-74$ years and $8.7 \%(95 \%$ CI: $7-11 \%$ ) in those 75 years and older. Overall, women report more depression than men $(12.5 \%, 95 \%$ CI: $11-14 \%$ vs. $7.2 \%, 95 \%$ CI: $6-8 \%$ ).

\section{Correlates of depressive symptoms}

There were significant differences in sociodemographic factors between participants with and without depressive symptoms (Table 1). Women had greater odds of being depressed than men (OR $=1.85,95 \%$ CI: $1.58,2.16$ ). Older participants were less likely than younger participants to have depressive symptoms $(\mathrm{OR}=0.84,95 \% \mathrm{CI}: 0.71,1.00$, for the category $65-74$ years; and OR $=0.79,95 \%$ CI: 0.64 , 0.98 , for the category $75+$, when compared with adults aged 50-64 years). Participants who had only completed primary level education were more likely than those with secondary or tertiary level to suffer with depressive symptoms $(\mathrm{OR}=1.62,95 \% \mathrm{CI}: 1.39$, 1.89 for primary when compared with adults with tertiary education). Never having married or been widowed separated or divorced were associated with increased odds of being depressed $(\mathrm{OR}=1.44,95 \%$ 
Table 1 Sociodemographic characteristics of older adults with and without depressive symptoms and univariate logistic regression analyses

\begin{tabular}{|c|c|c|c|c|c|c|c|c|c|}
\hline & & & & \multicolumn{2}{|c|}{ Nondepressed } & \multicolumn{2}{|c|}{ Depressed } & \multirow[b]{3}{*}{ OR } & \multirow[b]{3}{*}{$95 \% \mathrm{Cl}$} \\
\hline & & \multicolumn{2}{|c|}{ All sample } & \multicolumn{2}{|c|}{ CES-D $\leq 15$} & \multicolumn{2}{|c|}{ CES-D $\geq 16$} & & \\
\hline & & $n^{\mathrm{a}}$ & $\%^{\mathrm{b}}$ & $n^{\mathrm{a}}$ & $\%^{b}$ & $n^{a}$ & $\%^{b}$ & & \\
\hline Age (years) & $\begin{array}{l}\text { Mean(SD) } \\
50-64 \\
65+\end{array}$ & $\begin{array}{c}64(10) \\
4606 \\
3426\end{array}$ & $\begin{array}{l}58.4 \\
41.6\end{array}$ & $\begin{array}{l}64(10) \\
4118 \\
3141\end{array}$ & $\begin{array}{l}58.1 \\
41.9\end{array}$ & $\begin{array}{l}63(10) \\
488 \\
285\end{array}$ & $\begin{array}{l}63.1 \\
36.9\end{array}$ & 0.76 & $(0.65-0.89)$ \\
\hline Sex & $\begin{array}{l}\text { Male } \\
\text { Female }\end{array}$ & $\begin{array}{l}3688 \\
4344\end{array}$ & $\begin{array}{l}48.0 \\
52.0\end{array}$ & $\begin{array}{l}3435 \\
3824\end{array}$ & $\begin{array}{l}49.6 \\
50.4\end{array}$ & $\begin{array}{l}253 \\
520\end{array}$ & $\begin{array}{l}34.8 \\
65.2\end{array}$ & $1.85^{* *}$ & $(1.58-2.16)$ \\
\hline Education & $\begin{array}{l}\text { Primary } \\
\text { Secondary } \\
\text { Tertiary }\end{array}$ & $\begin{array}{l}2444 \\
3222 \\
2363\end{array}$ & $\begin{array}{l}38.3 \\
43.2 \\
18.5\end{array}$ & $\begin{array}{l}2133 \\
2941 \\
2182\end{array}$ & $\begin{array}{l}36.9 \\
44.0 \\
19.1\end{array}$ & $\begin{array}{l}311 \\
281 \\
181\end{array}$ & $\begin{array}{l}47.9 \\
38.0 \\
14.2\end{array}$ & $\begin{array}{l}1.62^{* *} \\
0.84\end{array}$ & $\begin{array}{l}(1.39-1.89) \\
(0.72-0.98)\end{array}$ \\
\hline Marital status & $\begin{array}{l}\text { Married } \\
\text { Never married } \\
\text { Widowed/separated/divorced }\end{array}$ & $\begin{array}{r}5560 \\
766 \\
1696\end{array}$ & $\begin{array}{r}67.8 \\
9.7 \\
22.5\end{array}$ & $\begin{array}{r}5143 \\
677 \\
1439\end{array}$ & $\begin{array}{r}69.8 \\
9.3 \\
20.9\end{array}$ & $\begin{array}{r}417 \\
99 \\
257\end{array}$ & $\begin{array}{l}53.1 \\
12.8 \\
34.2\end{array}$ & $\begin{array}{l}1.44 \\
2.00\end{array}$ & $\begin{array}{l}(1.14-1.79) \\
(1.71-2.35)\end{array}$ \\
\hline Medical card & & 3948 & 52.4 & 3442 & 50.3 & 506 & 68.4 & & \\
\hline Private medica & surance & 3246 & 36.6 & 3060 & 38.7 & 186 & 21.0 & & \\
\hline
\end{tabular}

"Unweighted counts.

Weighted percentages.

${ }^{*} p \leq 0.05,{ }^{* *} p \leq 0.001$.

CI: $1.14,1.79$ for never married; and $\mathrm{OR}=2.0,95 \%$ CI: $1.71,2.35$, for been widowed separated or divorced when compared with been married).

Univariate logistic regression analyses of clinical characteristics on depressive symptoms can be seen in Table 2. The odds of depressive symptoms increased as the number of chronic diseases increased
$(\mathrm{OR}=1.31,95 \% \mathrm{CI}: 1.25,1.37)$ and in the presence of an LLI $(\mathrm{OR}=4.18,95 \% \mathrm{CI}$ : $3.58,4.86)$. Other health-related (smoking, number of medications, pain, urinary incontinence and sensory impairment) and cognitive (poor recall and poor verbal fluency) factors were also significantly related to increased odds of being depressed.

Table 2 Clinical characteristics of older adults with and without depressive symptoms and univariate logistic regression analyses

\begin{tabular}{|c|c|c|c|c|c|c|}
\hline & \multirow{2}{*}{\multicolumn{2}{|c|}{$\begin{array}{r}\text { Nondepressed } \\
\text { CES-D } \leq 15\end{array}$}} & \multirow{2}{*}{\multicolumn{2}{|c|}{$\begin{array}{l}\text { Depressed } \\
\text { CES-D } \geq 16\end{array}$}} & \multirow[b]{3}{*}{ OR } & \multirow[b]{3}{*}{$95 \% \mathrm{Cl}$} \\
\hline & & & & & & \\
\hline & Mean & SE & Mean & SE & & \\
\hline Number of medications & 2.4 & 0.03 & 3.9 & 0.12 & $1.17^{*}$ & $(1.15-1.20)$ \\
\hline Immediate recall & 5.7 & 0.02 & 5.3 & 0.06 & 0.88 & $(0.84-0.92)$ \\
\hline Delayed recall & 5.9 & 0.03 & 5.3 & 0.08 & 0.89 & $(0.87-0.92)$ \\
\hline \multirow[t]{2}{*}{ Number of chronic diseases } & 1.6 & 0.02 & 2.3 & 0.06 & $1.31^{* *}$ & $(1.25-1.37)$ \\
\hline & $n^{a}$ & $\%^{\mathrm{b}}$ & $n^{a}$ & $\%^{\mathrm{b}}$ & OR & $95 \% \mathrm{Cl}$ \\
\hline Low verbal fluency & 393 & 6.2 & 75 & 10.6 & $1.92^{* *}$ & $(1.48-2.47)$ \\
\hline Limiting long illness & 1442 & 20.0 & 395 & 49.7 & $4.18^{* *}$ & $(3.59-4.86)$ \\
\hline Chronic pain & 1610 & 22.2 & 396 & 51.3 & $3.69^{* *}$ & $(3.17-4.30)$ \\
\hline Incontinence & 582 & 8.0 & 161 & 20.8 & $3.02^{* *}$ & $(2.49-3.66)$ \\
\hline Smokes & 1208 & 16.6 & 248 & 31.9 & $2.35^{* *}$ & $(2.00-2.77)$ \\
\hline Poor vision & 2939 & 40.4 & 426 & 54.8 & $3.02^{* *}$ & $(2.50-3.65)$ \\
\hline Poor hearing & 2832 & 39.0 & 359 & 46.2 & $1.51^{* *}$ & $(1.24-1.82)$ \\
\hline
\end{tabular}

"Unweighted counts.

Weighted percentages.

$*_{p} \leq 0.05, * *_{p} \leq 0.001$. 


\section{Multivariate analysis}

The factors that attained statistical significance in the univariate analyses were then included in a series of multivariate logistic regression models for men and women separately and stratified by age group (Tables 3 and 4). Table 5 shows the $p$-values for tests of the interactions between each factor and age and sex when the final model was estimated across all participants.

In the first step of each regression analysis, significant demographic variables were entered as predictors (age, having only primary education and marital status). In the second step, health-related factors including verbal fluency, immediate recall, number of chronic conditions, alcohol/substance abuse and smoking were added to the model. In the presence of these additional factors, education remained significantly associated with depressive symptoms only in adult women aged 50-64 years, whereas all other associations remained stable. Step 3 involved adding factors associated with chronic conditions such as number of medications, presence of an LLI, chronic pain, incontinence and sensory impairment. Some associations seen in the fully adjusted models differed significantly by sex and age category.

\section{Age and sex differences in clinical factors}

Cognitive function. Verbal fluency was associated with depression only in men and women who are 65 years and older. Immediate recall was associated with depression in women of all ages, but no association was observed in men.

Physical illness and medication use. Physical illness was associated with depression in the partially adjusted model (model 2) for both men and women of all ages. However, in the fully adjusted model, physical illness was associated with depression only in men and women who are 65 years and older. The inclusion of medications in the full model caused the association between physical illness and depression to lose significance for younger adults aged 50-64 years.

Differences in the effects of physical illness and of medication use were significantly different by age group $(p<0.001)$. The effects of pain and incontinence, although statistically significant in both sexes, were significantly stronger predictors of depressive symptoms in men than women ( $p<0.001$ for interaction terms). Smoking was associated with depressive symptoms only in women, and this sex difference was significant (Table 5).

\section{Discussion}

Overall in this population-based study of older Irish adults, we found that $10 \%$ of adults 50 years and older reported clinically significant depressive symptoms with a higher prevalence of depressive symptoms observed amongst women in all age groups.

Regardless of age and gender, chronic pain, disability, visual impairment and urinary incontinence are the most consistent correlates of depressive symptoms found in this study. Substantial evidence already exists in the literature linking pain and functional disability with depressive symptoms (Geerlings et al., 2002, Yang and George, 2005); however, the association between incontinence and depressive symptoms is not well documented, particularly in men. Urinary incontinence is a significant health problem for older adults, and the prevalence increases significantly with age (Roberts et al., 1998). It is also a common reason for admission to residential care where the prevalence of depressive symptoms is known to be much higher. Some studies (Sims et al., 2011) suggest that incontinence is only associated with depressive symptoms in older women; however, our findings suggest that incontinence is strongly associated with depressive symptoms in both men and women, and this finding is strengthened by the fact that the analysis controlled for limitations to physical mobility. Moreover, we found that among both age groups, incontinence was more strongly associated with depressive symptoms among men than women. Depression was seen in $20 \%$ of those reporting incontinence, suggesting that adults presenting for treatment of urinary incontinence should be screened for depression and greater awareness and treatment of incontinence in older adults could potentially reduce the prevalence of depression.

In our study, visual impairment was associated with depressive symptoms in all adults, whereas hearing impairment was not associated with depressive symptoms after adjusting for all other factors. We might have expected visual impairment to be associated with depressive symptoms only in those aged 50-64 years, given the literature (Rees et al., 2010) suggesting it is the age at which individuals are dealing with loss that is critical to the development of depression. However, our results suggest that vision-specific distress is associated with depressive symptoms in all older adults regardless of age. Identifying older adults with high levels of distress from visual impairment could be a way to determine those at risk of depression and in need of early intervention. Older adults may benefit from early interventions focused on coping and dealing with the practical and social burden associated 

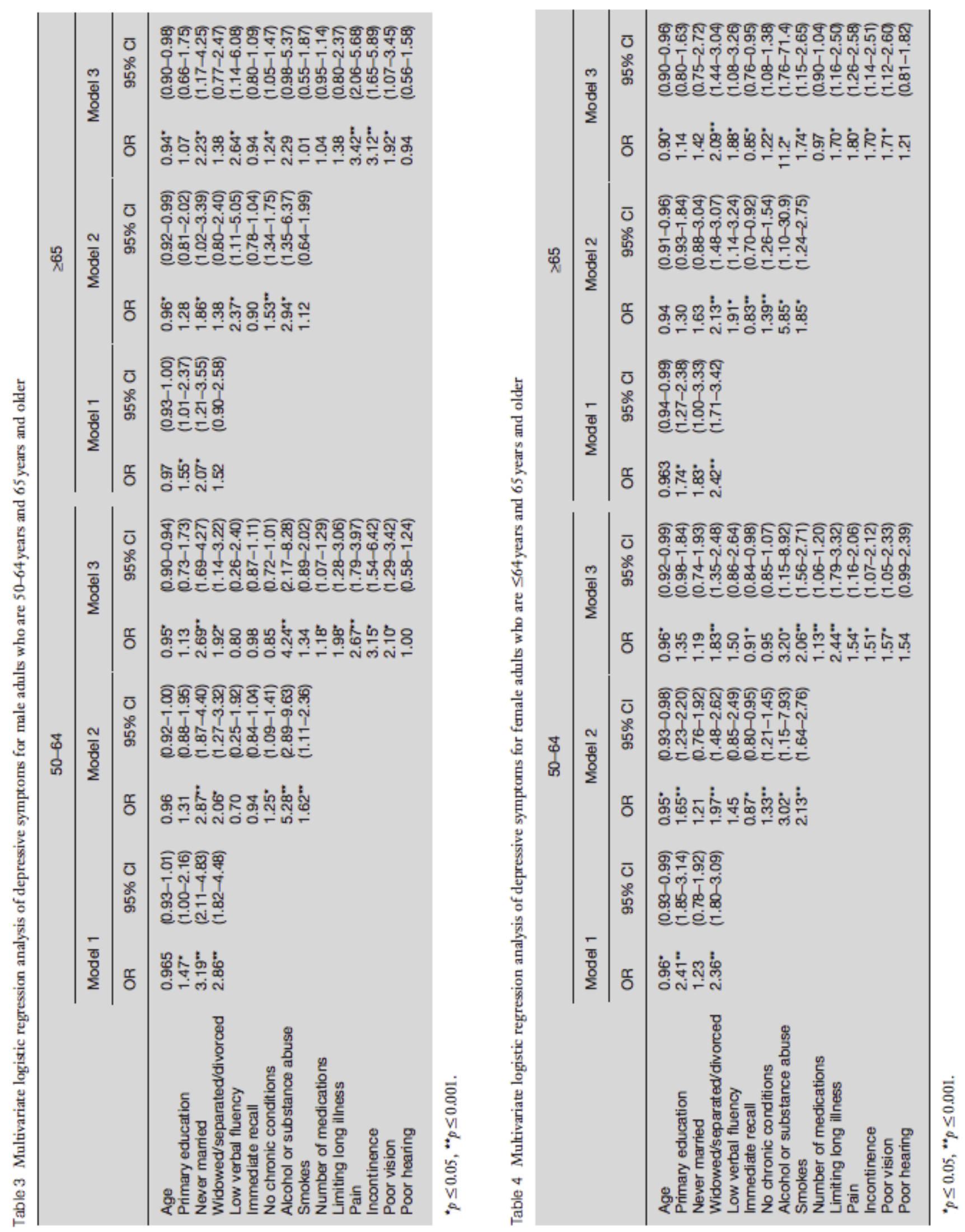
Table 5 The $p$-values for interactions terms in the final model

\begin{tabular}{|c|c|c|}
\hline & \multirow{2}{*}{$\begin{array}{l}\text { Age group } \\
\rho \text {-value }\end{array}$} & \multirow{2}{*}{$\frac{\text { Sex }}{p \text {-value }}$} \\
\hline & & \\
\hline Age & 0.40 & 0.76 \\
\hline Education & 0.57 & 0.67 \\
\hline Never married & 0.98 & 0.01 \\
\hline Widowed/separated/divorced & 0.87 & 0.66 \\
\hline Low fluency & 0.19 & 0.53 \\
\hline Immediate recall & 0.28 & 0.18 \\
\hline Chronic disease & 0.00 & 0.56 \\
\hline Substance abuse & 0.71 & 0.63 \\
\hline Smoker & 0.28 & 0.03 \\
\hline Medications & 0.00 & 0.59 \\
\hline Limiting illness & 0.13 & 0.43 \\
\hline Pain & 0.42 & 0.00 \\
\hline Incontinence & 0.63 & 0.00 \\
\hline Poor vision & 0.92 & 0.25 \\
\hline Poor hearing & 0.83 & 0.22 \\
\hline
\end{tabular}

with visual or hearing impairment rather than being treated for depression.

In building our model of depression, we developed three steps that represented sociodemographic variables, chronic disease factors and conditions or factors that may mediate the effect of chronic disease on depression. This procedure generated some statistically significant differences in the association between physical illness and medications across age groups. Among those aged 50-64 years, the relationship between physical illness and depressive symptoms appears to be accounted for by medication use. This is in direct contrast to what is observed in adults 65 years and older where physical illness remains significantly associated with depression despite the inclusion of medications in the model. These results might suggest that in adults aged 50-64 years, it is the medications taken for chronic diseases that account for some of the increased risk for depression associated with comorbid physical illness. Future work will focus on whether this association is related to polypharmacy or the nature and dosage of specific medications.

Low verbal fluency was associated with depressive symptoms only in adults 65 years and older, although this age difference was not statistically significant (interaction effect $p=0.19$ ). These results are in keeping with previous findings of a strong association between depression and executive dysfunction in older adults (Alexopoulos et al., 2002). Interestingly, memory (measured by immediate recall) was associated with depressive symptoms only in women. It is possible that women may be more susceptible to the psychological and emotional impact of memory impairment although again the gender difference was not statistically significant. The causal and temporal relationship between depressive symptoms and cognitive function is currently of great research interest, and results thus far yield mixed findings. Future waves of TILDA will add to the evidence base in this area.

Depression is associated with cerebrovascular disease, and as a result, there is increasing interest in the potential role that risk factors for cerebrovascular disease might play in facilitating the clinical expression of depression (Thomas et al., 2004). Cigarette smoking is an important, but potentially reversible, risk factor for cardiovascular diseases. The link between smoking and depression has been well documented in young people; however, smoking research and intervention efforts have largely neglected older adults, with older women particularly underserved (Brown et al., 2004, Donze et al., 2007). Our results extend the evidence base by showing that current smoking is much more strongly associated with depressive symptoms in women than men ( $p$-value for gender difference, 0.03 ). Throughout adulthood, women show higher levels of depressive disorders than men and women are more prone to engage in negative affect-related smoking and to show stronger relations of life stressors to smoking maintenance or relapse (Livson and Leino, 1988, McKee et al., 2003). For these reasons, the most plausible interpretation of our results is that in older adult women, it is depressed mood that increases smoking risk rather than smoking behaviour leading to depression and that treatment of low mood may be a target for smoking cessation among older women.

Strengths of the present study are the very large nationally representative sample with a high response rate and the comprehensive assessment of healthrelated and sociodemographic factors. A response rate of $60 \%$ is used as the threshold of acceptability for most journals; therefore, our response rate of $62 \%$ is robust for a study of older adults, given that survey response rates have been in steep decline for several years (Johnson and Wislar, 2012). Limitations are that the data were analysed cross-sectionally, and although we have used modification of regression effects to attempt to identify mediating relationships, we cannot make any direct inferences about causality. Depression was not formally diagnosed in our study; however, the CES-D instrument has been shown to have good validity with respect to depression in the older population, and CES-D is a well-validated measure of depressive symptomatology. Additionally, findings from a recent review of risk factors for depression (Vink et al., 2008) showed no clear differences between risk factors for depressive symptoms and disorders, suggesting that these risk 
factors are significant for the whole continuum of severity of depression.

In summary, we have identified age-specific and gender-specific clinical correlates of depressive symptoms among the older population, which may identify those most likely to present with depression in community settings. Some of the factors found to be associated with depression are potentially modifiable, in particular visual impairment and incontinence. Given the rapidly expanding population of older adults and the burden of morbidity represented by depression, more research is needed to fully understand the effects of these potentially modifiable factors and how they can be targeted to alleviate depression in the older population.

\section{Key points}

- In older adults, the risk of depression is increased by physical illness; however, the nature of this relationship is complex and unclear.

- Older adults are not a homogenous group, and some clinical correlates of depressive symptoms show specific age and gender distribution patterns.

- Physical illness is associated with depressive symptoms only in older adults (65+)-the association is mediated by medication use in adults aged $50-64$ years.

- Pain and incontinence are stronger predictors of depressive symptoms in men compared with women.

\section{Acknowledgements}

The authors would like to acknowledge the contribution of the participants in the study, members of the TILDA research team, study nurses and administrators. Funding is from The Atlantic Philanthropies, Irish Life plc and the Irish Government.

\section{Conflicts of interest}

There are no conflicts of interests to report.

\section{References}

Alexopoulos GS, Meyers BS, Young RC, ef al. 1997. 'Vascular depression' hypothesis. Arch Gen Psychiatry 54, 915-22.

Alexopoulos GS, Kiosses DN, Klimstra S, Kalayam B, Bruce ML. 2002. Clinical presentation of the "depression-executive dysfunction syndrome" of late life. Am J Geriatr Psychiatry 10: 98-106.
Beekman AT, Deeg DJ, Smit JH, Van Tilburg, W. 1995a. Predicting the course of depression in the older population: results from a community-based study in The Netherlands. I Affect Disord 34: 41-9.

Beekman AT, Deeg DJ, Van Tilburg T, ef al. 1995b. Major and minot depression in later life: a study of prevalence and risk factors. / Affect Disord 36: 65-75.

Beekman AT, Kriegsman DM, Deeg DJ, Van Tilburg W. 1995c. The association of physical bealth and depressive symptoms in the older pogulation: age and sex differences. Soc Psychiarty Psychiatr Epidemial 30: 32-8.

Beekman AT, Deeg DJ, Van Limbeek J, et al. 1997. Criterion validity of the Center for Epidemiologic Studies Depression scale (CFS-D): results from a community-based sample of older subjects in The Netherlands. Psychol Med 27: 231-5.

Blazer DG. 2003. Depression in late life: review and commentary. J Gerontol A Biol Sc Med Sci 58: 249-65.

Brodaty H, Luscombe G, Parker G, ef al. 2001. Early and late onset depression in old age: different aetiologies, same phenomenology. J Affect Disord 66: 225-36.

Brown DW, Croft JB, Schendk AP, ef al. 2004. Inpatient smoking-cessation counseling and all-cause mortality among the elderly. Am I Prer Med 26: 112-8.

Bruce, ML, Mcavay, GJ, Raue, PJ, ef al. 2002. Major depression in elderly home health care patients. Am I Psychiatry 159: $1367-74$.

Cummings J1. 1992. Depression and Parkinson's disease: a review. Am J Psychiatry 149: 443-54.

Djernes JK. 2006. Prevalence and predictors of depression in populations of elderly: a review. Acta Psychiatr Scand 113: 372-87.

Donze J, Ruffieux C, Cornuz J. 2007. Determinants of smoking and cessation in older women. Age Ageing 36: 53-7.

Fiske A, Wetherell JL, Gatz M. 2009. Depression in older adults. Annu Rev Clin Psychol 5: 363-89.

Geerlings SW, Twisk IW, Beekman AT, Deeg DJ, Van TIburg W. 2002. Longitudinal relationship between pain and depression in older adults: sex, age and physical disebility. Soc Psychiatry Psychiatr Epidemiol 37: 23-30.

Hasin DS, Goodwin RD, Stinson FS, Grant BE. 2005. Epidemiology of major depressive disorder: results from the National Epidemiologic Sarvey on Alcobolism and Related Conditions. Arch Gen Psychiatry 62: 1097-106.

Johnson TP, Wislar JS. 2012. Response rates and nonresponse errors in surveys. IAMA 307: 1805-6.

Kearney PM, Cronin H, O'Regan $\mathrm{C}_{3}$ et al. 2011. Cohort profile: the Irish Longitudinal Study on Ageing. Int / Epidemiol 40: 877-84.

Kennedy GJ, Kelman HR, Thomas C, ef al. 1989. Hierarchy of characteristics associated with depressive symptoms in an urban elderly sample. Am J Psychiatry 146: $220-5$.

Licht-Strunk E, Van Der Kooij KG, Van Schaik DJ, et al. 2005. Prevalence of depression in older potients consulting their general practitioner in The Netherlands. Int $f$ Geriatr Psychiatry 20: 1013-9.

Livson N, Leino EV. 1988. Cigarette smoking motives: factorial structure and gender differences in a longitudinal study. Int J Addiat 23: 535-44.

Mckee SA, Maciejewski PK, Falha T, Mazure CM. 2003. Sex differences in the effects of stressful life events on changes in smoking status. Adlaction 98: 847-55.

Murray CJ, Lopez AD. 1997. Alternative projections of mortality and disability by cause 1990-2020: Global Burden of Disease Study. Lancet 349: 1498-504.

Ofstedal M, Fisher G, Herzog AR. 2005. Documentation of cognitive functioning measures in the health and retirement study. Available: [http:/hrsonline.isr. umich.edu/sitedocs/userg/dr-006.pdf).

Park M, Unützer J. 2011. Geriatric depression in primary care. Psychiatr Clin North Am 34: 469-x.

Prince MI, Harwood RH, Blizard RA, Thomas A, Mann AH. 1997. Impairment, disability and handicap as risk factors for depression in old age. The Gospel Oak Project V. Psychol Med 27: 311-21.

Rees G, Tee HW, Marella M, et al. 2010 Vision-specific distress and depressive symptoms in people with vision impairment. Invest Ophthalmol Vis Sd 51: 2891-6.

Roberts RO, Jacobsen Sj, Rhodes $T$, et al. 1998. Urinary incontinence in community-based cohort: prevalence and healthcare-seeking. I Am Geriatr So 46: $467-72$.

Schoevers RA, Beekman AT, Deeg DI, et al. 2000. Risk factors for depression in later life, results of a prospective community based study (AMSTEL). I Affect Disorid 59: $127-37$.

Sims J. Browning C, Lundgren-Lindquist B, Kendig H. 2011. Urinary incontinence in a community sample of older adults: prevalence and impact on quality of life. Disabil Rehabil 33: 1389-98.

Steptoe A, Breeze E, Banks J, Nazroo J. 2012. Cohort profile: The English Longitudinal Study of Ageing. Int $J$ Epidemid doi: 10.1093/jje/dys168.

Thomas AJ, Kalaria RN, O'brien JT. 2004. Depression and vascular disease: what is the relationship? J Affect Disord 79: 81-95.

Van't Veer-Tazelaar PJ, Van Marwijk HW, Jansen AP, ef al. 2008. Depression in old age (75+), the PIKO study. I Affect Disord 106: 295-9.

Vink D, Aartsen M), Schoevers RA. 2008. Risk factors for anxiety and depression in the elderly: a review. $J$ Affect Disord 106: 29-44.

Yang Y, George L.K. 2005. Functional disability, disability transitions, and depressive symptoms in late life. I Aging Health 17: 263-92. 